\title{
Early influence of auditory stimuli on upper-limb movements in young human infants: an overview
}

\author{
Priscilla A. M. Ferronato ${ }^{1,2}$ *, Erik Domellöf $^{3}$ and Louise Rönnqvist ${ }^{3}$ \\ ${ }^{1}$ Department of Pedagogy of Human Movement, São Paulo University, São Paulo, Brazil \\ 2 Physical Education Course, Institute of Health Sciences, Paulista University, São Paulo, Brazil \\ ${ }^{3}$ Department of Psychology, Umeå University, Umeå, Sweden
}

\section{Edited by:}

Rana Esseily, Université Paris Ouest Nanterre la Defense, France

Reviewed by:

Moritz M. Daum, University of Zurich, Switzerland

Joëlle Provasi, Ecole Pratique des

Hautes Etudes, France

\section{${ }^{*}$ Correspondence:}

Priscilla A. M. Ferronato, Physical Education Course, Institute of Health Science, Paulista University, Avenida Yogiro Takaoka 3500, 06541-038 Santana de Parnaíba, São Paulo, Brazil e-mail: pamalves@uol.com.br
Given that the auditory system is rather well developed at the end of the third trimester of pregnancy, it is likely that couplings between acoustics and motor activity can be integrated as early as at the beginning of postnatal life. The aim of the present mini-review was to summarize and discuss studies on early auditory-motor integration, focusing particularly on upper-limb movements (one of the most crucial means to interact with the environment) in association with auditory stimuli, to develop further understanding of their significance with regard to early infant development. Many studies have investigated the relationship between various infant behaviors (e.g., sucking, visual fixation, head turning) and auditory stimuli, and established that human infants can be observed displaying couplings between action and environmental sensory stimulation already from just after birth, clearly indicating a propensity for intentional behavior. Surprisingly few studies, however, have investigated the associations between upper-limb movements and different auditory stimuli in newborns and young infants, infants born at risk for developmental disorders/delays in particular. Findings from studies of early auditory-motor interaction support that the developing integration of sensory and motor systems is a fundamental part of the process guiding the development of goal-directed action in infancy, of great importance for continued motor, perceptual, and cognitive development. At-risk infants (e.g., those born preterm) may display increasing central auditory processing disorders, negatively affecting early sensorymotor integration, and resulting in long-term consequences on gesturing, language development, and social communication. Consequently, there is a need for more studies on such implications.

Keywords: review, auditory-motor interaction, upper-limb movements, newborns, infants, development, atypical development

\section{INTRODUCTION}

Infants can use multisensory systems from birth (Condon and Sander, 1974; Winkler et al., 2009; Aglioti and Pazzaglia, 2010), utilize environmental information and create new synergies in their action repertoire (e.g., searching behavior with the head and eyes, pre-reaching, and kicking). This developing integration of sensory and motor systems is a fundamental part of the process guiding the development of goal-directed action in infancy. Perception-action studies from birth onward are of critical importance for increased understanding of the developmental processes that underlie the interrelated human motor- and socio-cognitive development. Further, in the case of atypical development, such knowledge is important for early detection of sensory deviances and maturational delays, and for developing effective test protocols and appropriate intervention programs. Whilst the majority of studies of coupling between perception and action in infants have used essentially visual or multimodal perception paradigms, some studies have also found couplings between infant body movements and auditory stimuli (Birns et al., 1965; Condon and Sander, 1974; Fogel and Hannan, 1985; Fernald, 1989; Masataka, 1995; Ejiri and Masataka, 2001; Phillips-Silver and Trainor, 2007).
During the past decades, most studies of typical upper-limb movement development have focused on the developmental processes of intentional, object-oriented (i.e., pre-, reaching/grasping) and/or social-oriented communicative behaviors (i.e., gestures/pointing) pre-dominantly in infants from 4 to 5 months of age and onward. Others, mainly from a clinical perspective, have extensively studied spontaneous movement patterns (in fetuses, neonates, and young infants) referred to as general movements (GMs). GMs comprised of a series of gross movements of variable speed and amplitude that involve all body parts. Developmentally, GMs display age-specific characteristics, including so-called "preterm," "writhing," and "fidgety" arm movements (Hadders-Algra and Prechtl, 1992). It has been found that the quality and appearance of abnormal GMs are associated with an increased risk of minor neurological dysfunction (HaddersAlgra and Groothuis, 1999). In infants born preterm, delays in the development of reaching and grasping are found to be more common (Thun-Hohenstein and Largo, 1991) as well as reaches with non-optimal kinematic characteristics at the ages of 6-12 months (Fallang and Saugstad, 2003; Rönnqvist and Domellöf, 2006; Grönqvist et al., 2011). Still, although many scholars in the past 
have pinpointed the evolutionary importance of auditory-motor interactions for human development of gesturing, language and social interaction, few have included the influences of sounds when investigating upper-limb-movements and/or GMs in neonates and young infants, and more recent studies of early auditory-motor interactions are surprisingly rare. Given that the auditory system is rather well developed at the end of the third trimester of pregnancy, it is likely that couplings between acoustics and motor activity can be integrated as early as at the beginning of postnatal life and help motivate environment interaction. Consequently, the study of auditory-motor interactions in infancy stands out as highly relevant from both a theoretical and a clinical perspective.

This mini-review aims to summarize and discuss the emergence of auditory-motor interaction and coordination in typically developing newborns and young infants up to 6 months-old, specifically with regard to studies covering behaviors in the upperextremities in association with auditory stimuli. A specific focus on the upper-extremities was selected as the acquisition of abilities in those limbs during motor development is of great importance for further possibilities for action in, and interaction with, the environment. The purpose is to present some of the research field on early active behavior and auditory-motor integration, and to bring further understanding for its significance for the developmental process during early infancy. Another purpose is to highlight the need for further studies focusing on infants at risk for developmental delays and deviations related to early auditory-motor interactions that may lead to negative long-term consequences.

\section{ACTIVE BEHAVIOR}

Even a simple movement involves a complex synergy between action, perception, and cognition in order to understand, construct, and produce a proficient action to successfully achieve the intended goal. Already from early stage development, human infants perform prospective actions following these principles (von Hofsten and Rönnqvist, 1988; Claxton et al., 2003). In newborns, simple actions such as head turning or single displacements of the limbs from one position to another are characterized by continuous velocity profiles, produced by a regular pattern of accelerations/decelerations (von Hofsten, 1993; von Hofsten and Rönnqvist, 1993; Lee, 2006). Still, relatively little research has been devoted to the coupling between motor action and various sensory stimuli in young infants when interacting with the environment. Several studies, however, suggest that early motor outputs are indeed to be seen as potentially intentional and controlled behaviors in interaction with environmental events, including sucking behavior (Kalnins and Bruner, 1973; DeCasper and Fifer, 1980; Walton et al., 1992; Rochat and Hespos, 1997; Bobin-Bègue et al., 2006), movement of the neck and head (Jouen, 1988), and leg movements (Thelen, 1981).

Active behavior has also been studied and identified with regard to arm movements displayed by healthy newborn infants (van der Meer et al., 1995; van der Meer, 1997). These findings provide support for an early focused control of arm movements guided by vision. With regard to reaching, and grasping behavior, there is currently no consensus in the literature about when newborns are able to couple arm and hand movements to environmental events and display intentional reaching action. Several studies have reliably confirmed intentional behavior during reaching and grasping in infants around 7-8-months-old (Lockman et al., 1984; von Hofsten and Fazel-Zandy, 1984; Pieraut-Le Bonniec, 1985; von Hofsten and Rönnqvist, 1988; Corbetta et al., 2000; Fagard, 2000). Other studies report similar intentionality in infants at around 4 months, as observed in prospective grasp-planning ability (Newell et al., 1989; Siddiqui, 1995; Barrett et al., 2008). In agreement with the latter reports, infants at 4 months display modulation of hand pressure relative to an object's rigidity (Rochat, 1983). Further, infants at 4 months appear sensitive to the position of objects when planning to grasp (Bruner and Koslowski, 1972; McDonnell, 1975). However, indications of intentional reaching have been noted even earlier. Another study observed oriented reaching toward seen objects in newborns, interpreted as an indication of intention (Bower et al., 1970). Trevarthen employed the term "pre-reaching" when observing a precise coordination between hands and fingers in infants' attempts to reach at around 2 months (Trevarthen, 1974). Pre-reaching was later longitudinally evaluated in newborns and infants over the ages 5-16 weeks showing that a reaching reaction directed to the object could be observed at 5 weeks, becoming increasingly intentional and active over the subsequent weeks (von Hofsten, 1984).

To summarize, the literature shows evidence that active behavior is observable from the very beginning of life and over early infancy, and couplings between perception and action are undoubtedly involved already in newborns' motor behavior.

\section{AUDITORY STIMULI AND BODY-BEHAVIOR INTERACTION}

Research on cross-modal perception in newborns and young infants has established an early coordination of hearing with other sense modalities (Wertheimer, 1961; Turkewitz et al., 1966; Bower etal., 1970; Mendelson and Hath, 1976; Crassini and Broerse, 1980; Fenwick and Morrongiello, 1998; Morrongiello et al., 1998). Most developmental perception-action studies have employed parallel intermodal matching of auditory-visual relationships when investigating early infant behaviors (Guihou and Vauclair, 2008). Few have studied the role of amodal sound information in relation to newborn motor activity and in coordination with the environment. Auditory experience begins at the start of the third trimester of pregnancy as the myelination process from the cochlear outlet up to the auditory thalamus occurs (Moore and Linthicum, 2007). As shown by ultrasound studies, fetal facial and body movements in response to acoustic stimulation can be observed from 25 to 27 th gestational weeks and with consistency during the following gestational weeks (Birnholz and Benacerraf, 1983; Kuhlman et al., 1988; Hepper and Shahidullah, 1994). The auditory system is therefore fairly developed at birth, but still immature during early infancy in terms of, e.g., restricted sensitivity to high-frequency sounds (Werner, 2007). This means that newborns and young infants (and fetuses) are more sensitive to low-frequency sounds such as speech and language (Hepper and Shahidullah, 1994). Indeed, studies have shown that fetuses display behavioral changes (heart rate deceleration) when exposed to low-pitch auditory stimuli (Lecanuet 
et al., 2000), may discriminate between male and female voices (Lecanuet et al., 1993), and that fetuses and newborns recognize the mother's voice after prenatal exposure (DeCasper and Fifer, 1980; Smith et al., 2007; Kisilevsky and Hains, 2011). This also implicates that speech stimuli may evoke different responses compared with other auditory stimuli that may be valuable to consider when investigating couplings between acoustics and motor activity in early postnatal life.

Studies of newborns and young infants have shown a relationship between various behaviors such as head turning, sucking, visual fixation, and auditory stimuli. The outcomes of these studies concurrently suggest that infants are able to change behaviors according to different sound conditions. For instance, newborns, and young infants are able to turn their heads toward a sound source (Chun et al., 1960; Siqueland and Lipsitt, 1966; Clifton et al., 1972; Muir and Field, 1979; Morrongiello and Fenwick, 1994). The most common explanation for this phenomenon is that newborns are born with some mechanism specific for turning to sound or for sound localization as a kind of innate reaction ability. None of these studies, however, have investigated or discussed the potential active components involved in head turning to sound (i.e., intentionally turning the head based on auditory information).

In studies comparing newborn sucking behavior and auditory stimuli, it has also been observed that sucking can vary according to auditory stimulation (Keen, 1964; Lipsitt and Kay, 1964). Active sucking in newborns has also been reported in association with a learning task during contingent or non-contingent presentation of speech sounds (Floccia et al., 1997), suggesting learning abilities through sucking behavior in operant conditioning. Moreover, study conditions involving speech sounds and/or where auditory stimuli is presented in a social context (e.g., mother's face in view and conversational interaction) seem to promote active sucking behavior in newborns (DeCasper and Fifer, 1980). Newborns and infants also move their eyes according to side of sound presentation (Turkewitz et al., 1966; Hammer and Turkewitz, 1975). Again, however, the discussion is based on innate components of turning to sound, with the young infant having a mainly passive role in the observed phenomenon.

In summary, according to most of the aforementioned studies, head, and facial movements of newborns and young infants seem to be displayed differently in association with auditory stimuli. However, few studies have considered that such behaviors can be used actively to interact with the environment in different auditory conditions, perhaps because it is not the most obvious function of this body region. Still, there seems to be some evidence of an early ability to be actively involved in exploratory activity and that newborns and young infants can perform perception-action sequences with different parts of the body according to acoustic conditions. In support of such statement, one study explored infant leg movements in relation to auditory stimuli (Stanley and Madsen, 1990), showing that infants (2-8 months old) could actively change auditory stimuli by changing their kicking behavior. The mother's voice was most commonly preferred, followed by a female voice, and then music. Infants learned how to change the acoustic stimuli and changed more often from non-preferred to preferred acoustic conditions.

\section{AUDITORY STIMULI AND UPPER-BODY BEHAVIOR INTERACTION}

A systematic search for English-language articles devoted to relation between auditory stimuli and upper-limb movements in infants up to 6 months between 1960 and 2014 was performed. A total of 18 articles were identified, derived from one or more of the following electronic databases: EBSCO, PubMed, Web of Science, Science Direct, OvidSP, Research Gate, and Google Scholar. The search terms used were a combination of: "auditory stimuli," "sound information," "arms movement," "arms behavior," "upper body movement," "manual behavior," "hand movement," "hand behavior," "newborn," "young infant," "infant." Additionally, the search was supplemented by exploring the reference list of included publications (see Table 1).

Undeniably, evidence for active use of the upper-extremities seems to be present from early infancy. For instance, one study showed that newborns at 2-6 days old performed different movement configurations with the arms, hands, and fingers when alternated between social, object presentation, and baseline conditions (Rönnqvist and von Hofsten, 1994). Analyses of the performed movements were in agreement with condition, showing more finger movements and flexions of the hands in the social condition, and more thumb-index finger activity and extension of the arms and hands in the object condition. Of relevance to the present review, mothers talked to their infants in the social condition (auditory stimulation available), and a small rattle was attached to the target object to initiate attention to the object. Thus, as in most studies of auditory-movement interaction in newborn/young infants striving for high ecological validity, other sources of stimulation were simultaneously available (e.g., visual stimuli).

Other studies have investigated whole body movements (including arm movements but not analyzed separately) in different auditory conditions (Collyer and Bench, 1974). Despite some inconsistencies between findings (Birns et al., 1965), likely due to methodological differences, these studies generally suggest that body movements, including arm movements, can be expressed in different ways according to various auditory stimulation from the beginning of life, as well as demonstrating acoustic preferences. Indeed, studies of newborn and infant body rhythm engagement in association with sound stimuli seem to confirm an early ability for bodily engagement with sound information in the environment (Condon and Sander, 1974; Zentner and Eerola, 2010). Additionally, in a recent study it was found that infants at 3-4-months-old interacted with music via limb movements and vocalizations, suggesting that the human brain is primed with the body to interact with music already at this age (Fujii et al., 2014).

Rhythmic arm movements in infants has gained a particular research interest in relation to the onset of reduplicated babble. At about 4-months-old, infants show a peak in rhythmic arm activity such as hand banging (Thelen, 1979), temporally coinciding with the age when infants begin to babble. The performance of rhythmic arm movements share common grounds with reduplicated babble in terms of producing organized and timed actions, and may provide multisensory feedback (including auditory from the infants' own sound production) that works in support of language 


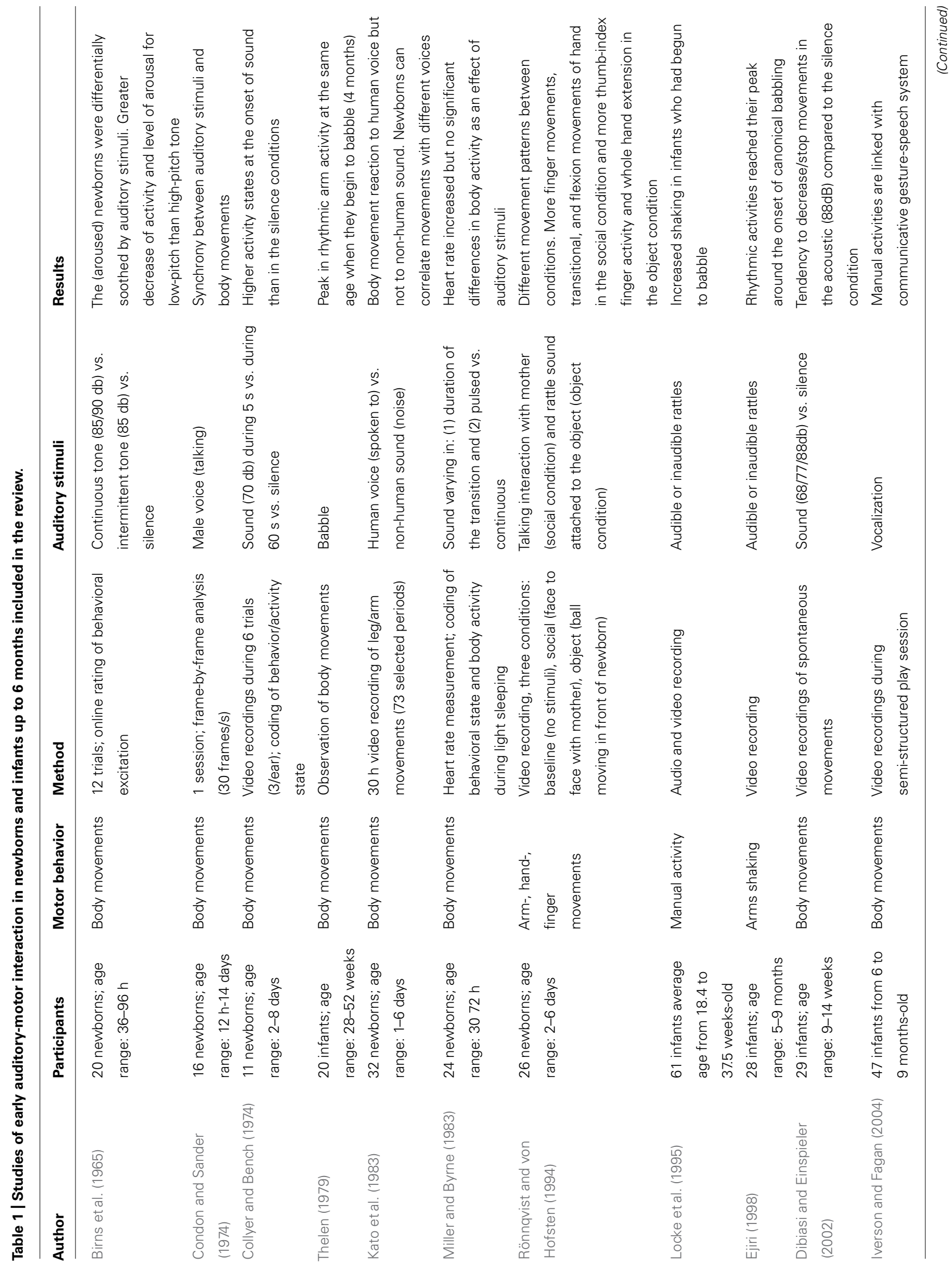




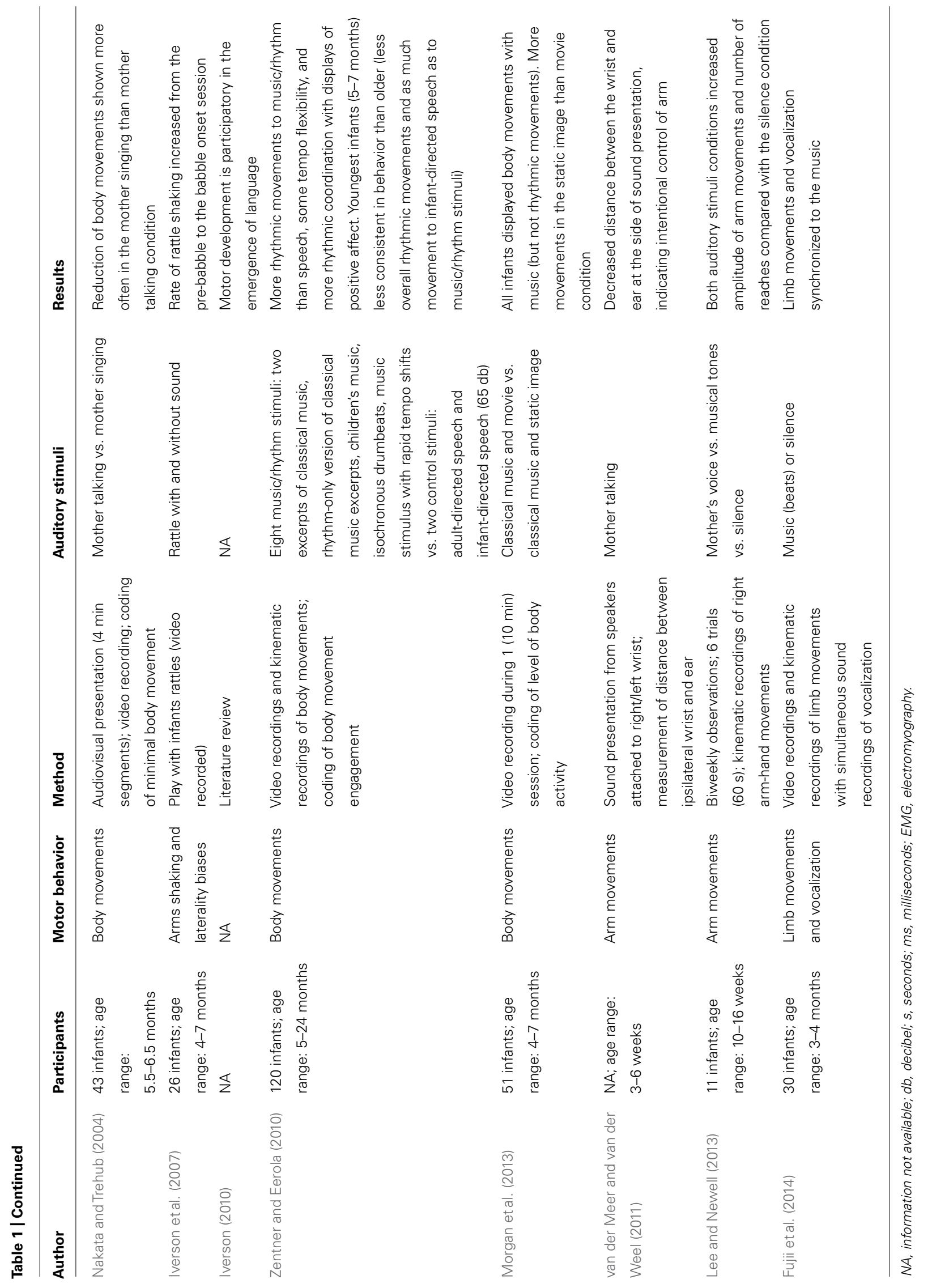


development (Iverson, 2010). Other studies showed an increase in infant rhythmic arm activity when leaving the pre-babbling age to onset of babbling, and a decline when becoming experienced babblers (Locke et al., 1995; Ejiri, 1998; Iverson et al., 2007; Iverson, 2010). Moreover, as babbling begins, vocal, and manual activities may be further linked and coordinated, underlying a later communicative gesture-speech system (Iverson and Fagan, 2004; Iverson et al., 2007). Thus, infant arm movements and vocalizations seem to be interrelated skills of importance to the acquisition of language.

Although specific investigations of arm movements in relation to auditory stimuli in younger infants are rare, one study observed that newborns from 3 to 6 weeks could control their arms to listen to the mother's voice according to the side of sound presentation (van der Meer and van der Weel, 2011). Mini-speakers were attached to the newborns' right and left wrists and the mother's voice was presented in either speaker. Measuring the distance between the ipsilateral wrist and ear, it was found that the distance between the wrist and ear decreased at the same side as the sound was presented. Recently, another study recorded the amplitude of arm movements to investigate if different auditory conditions (mother's voice, music, and silence) affected the reaching behavior in infants from 10 to 16 -weeks-old. The results showed that the amplitude of exploratory arm movements prior to reaching and the number of reaches increased in the mother's voice and music conditions compared with the silence condition (Lee and Newell, 2013). Taken together, these findings suggest that infants older than 3 weeks can integrate auditory information and display different arm movements depending on different sound conditions. The findings further suggest that infants are capable of using auditory information to explore action opportunities before executing goal-directed arm movements. It may thus be that multisensory connections between the auditory system and the motor system are underlying self-initiated spontaneous arms movements from very early in human life. Again, however, it must be considered that auditory stimulus was not the only information source to guide the motor system in these studies. Beyond the auditory information, visual information was also available, and thus, in parallel with the proprioceptive and haptic information, contributed to the organization of the infants' upper-body movements.

\section{DISCUSSION}

The general summation of this overview is that human newborns and young infants appear able to (1) link motor actions with sensory stimulation and perform goal-directed and prospective movements that are not simply reactive, (2) change body movements according to different auditory conditions, also in an active, explorative or preferential manner, and (3) at least from 3-weeksold, integrate auditory information and perform diverse arm movements depending on different sound conditions, possibly as a means of exploring action opportunities. However, the literature concerning auditory-motor interactions in young infants, particularly regarding upper-limb movements, and those that reflect the outcome of abnormal and/or delayed audio-manual-action development, is still limited.

The importance of advancing this research area becomes clear in the perspective of atypical development. Significant hearing loss is described as one of the most common disorders at birth, occurring in 1-2 per 1000 newborns (Korver etal., 2010) increasing the risk for delayed language development, difficulties with behavior and psychosocial interactions, and poor academic achievement. Infants born preterm and/or with very low birth weight are also at increased risk for hearing loss, associated with central auditory processing disorders that hamper ability to discriminate simple speech sounds and limit auditory memory span (Davis et al., 2001). Alternatively, they may experience progressive or delayed-onset hearing loss (Cristobal and Oghalai, 2008). These difficulties may have a negative effect on early sensory-motor integration, gesturing and social communication, and the acquisition and development of language skills and learning. Thus, further longitudinal studies, starting from an early postnatal age, to investigate the effect on auditory-movement interaction in at-risk infants are needed. It is of high importance to discover delayed auditive maturation and/or immature auditory pathways early (screening for hearing loss in the newborn allowing for earlier interventions and relevant hearing aids), as such conditions may lead to both short- and longterm consequences for auditory-movement interaction and coordination, with implications for further social and cognitive development.

\section{CONCLUSION}

The relationships between auditory (sensory) information and motor execution have an essential function for the integration of and adaptation between internal and external information in human newborns and young infants, and play a significant role for the developmental process of social interaction and communication, language acquisition, and further cognitive performance. Whilst several important observations of auditory-motor interactions in infancy have been made, lately also with regard to upper-limb movements, more studies are warranted. In this effort, a particular focus should be put on the effects/developmental processes in infants at risk for developmental delays and/or sensory deviations affecting multisensory and motor integration from an early age onward.

\section{AUTHOR CONTRIBUTIONS}

Priscilla A. M. Ferronato was in charge of the primary literature search and selection of relevant articles, contributed in the summation, integration and discussion, prepared the first draft of the paper, and approved the final draft as submitted. Erik Domellöf contributed in the selection of relevant articles, contributed in the summation, integration and discussion, co-wrote, reviewed, and revised the manuscript, and approved the final draft as submitted. Louise Rönnqvist contributed in the selection of relevant articles, contributed in the summation, integration, and discussion, cowrote, reviewed, and revised the manuscript, and approved the final draft as submitted.

\section{ACKNOWLEDGMENTS}

The authors disclose receipt of financial support from the Swedish Research Council (Dnr: 2011-179) and CAPES, Brazil (Process 1592412-2). 


\section{REFERENCES}

Aglioti, S. M., and Pazzaglia, M. (2010). Representing actions through their sound. Exp. Brain Res. 206, 141-151. doi: 10.1007/s00221-010-2344-x

Barrett, T. M., Traupman, E., and Needham, A. (2008). Infants' visual anticipation of object structure in grasp planning. Infant Behav. Dev. 31, 1-9. doi: 10.1016/j.infbeh.2007.05.004

Birnholz, J. C., and Benacerraf, B. R. (1983). The development of human fetal hearing. Science 222, 516-518. doi: 10.1126/science.6623091

Birns, B., Blank, M. W., Bridger, H., and Escalona, S. K. (1965). Behavioral inhibition in neonates produced by auditory stimuli. Child Dev. 36, 639-645. doi: $10.2307 / 1126910$

Bobin-Bègue, A., Provasi, J., Marks, A., and Pouthas, V. (2006). Influence of auditory tempo on the endogenous rhythm of non-nutritive sucking. Eur. Rev. Appl. Psychol. 56, 239-245. doi: 10.1016/j.erap.2005.09.006

Bower, T. G. R., Broughton, J. M., and Moore, K. M. (1970). Demonstration of intention in the reaching behaviour of neonate humans. Nature 228, 679-681. doi: $10.1038 / 228679 \mathrm{a} 0$

Bruner, J. S., and Koslowski, B. (1972). Visually preadapted constituents of manipulatory action. Perception 1, 3-14. doi: 10.1068/p010003

Chun, R. W. M., Pawsat, R., and Forster, F. M. (1960). Sound localization in infancy. J. Nerv. Ment. Dis. 130, 472-476. doi: 10.1097/00005053-196006000-00006

Claxton, L. J., Keen, R., and McCarty, M. E. (2003). Evidence of motor planning in infant reaching behavior. Psychol. Sci. 14, 354-356. doi: 10.1111/1467-9280. 24421

Clifton, R. K., Siqueland, E. R., and Lipsitt, L. P. (1972). Conditioned headturning in human newborns as a function of conditioned response requirements and states of awakeness. J. Exp. Child Psychol. 13, 43-57. doi: 10.1016/0022-0965(72) 90006-9

Collyer, Y., and Bench, J. (1974). Newborn's responses to auditory stimuli judged in relation to stimulus onset and offset. Br. J. Audiol. 8, 14-17. doi: 10.3109/03005367409086945

Condon, W. S., and Sander, L. W. (1974). Neonate movement is synchronized with adult speech: interactional participation and language acquisition. Science 183, 99-101. doi: 10.1126/science.183.4120.99

Corbetta, D., Thelen, E., and Johnson, K. (2000). Motor constraints on the development of perception-action matching in infant reaching. Infant Behav. Dev. 23, 351-374. doi: 10.1016/S0163-6383(01)00049-2

Crassini, B., and Broerse, J. (1980). Auditory-visual integration in neonates: a signal detection analysis. J. Exp. Child Psychol. 29, 144-155. doi: 10.1016/00220965(80)90097-1

Cristobal, R., and Oghalai, J. S. (2008). Hearing loss in children with very low birth weight: current review of epidemiology and pathophysiology. Arch. Dis. Child. 93, F462-F468. doi: 10.1136/adc.2007.124214

Davis, N. M., Doyle, L. W., and Ford, G. W. (2001). Auditory function at 14 years of age of very-low birthweight children. Dev. Med. Child Neurol. 43, 191-196. doi: 10.1111/j.1469-8749.2001.tb00186.x

DeCasper, A. J., and Fifer, W. P. (1980). Of human bonding: newborns prefer their mothers' voices. Science 208, 1174-1176. doi: 10.1126/science.7375928

Dibiasi, J., and Einspieler, C. (2002). Can spontaneous movements be modulated by visual and acoustic stimulation in 3-month-old infants? Early Hum. Dev. 68, 27-37. doi: 10.1016/S0378-3782(02)00010-5

Ejiri, K. (1998). Relationship between rhythmic behavior and canonical babbling in infant vocal development. Phonetica 55, 226-237. doi: 10.1159/000028434

Ejiri, K., and Masataka, N. (2001). Co-occurrence of preverbal vocal behavior and motor action in early infancy. Dev. Sci. 4, 40-48. doi: 10.1111/1467-7687. 00147

Fagard, J. (2000). Linked proximal and distal changes in the reaching behavior of 5 to 12-month-old human infants grasping objects of different sizes. Infant Behav. Dev. 23, 317-329. doi: 10.1016/S0163-6383(01)00047-9

Fallang, B., and Saugstad, O. D. (2003). Kinematic quality of reaching movements in preterm infants. Pediatr. Res. 50, 875-882. doi: 10.1203/01.PDR.0000058925.94994.BC

Fenwick, K. D., and Morrongiello, B. A. (1998). Spatial co-localization and infants' learning of auditory-visual associations. Infant Behav. Dev. 21, 745-759. doi: 10.1016/S0163-6383(98)90042-X

Fernald, A. (1989). Intonation and communicative intent in mothers' speech to infants: is the melody the message? Child Dev. 60, 1497-1510. doi: $10.2307 / 1130938$
Floccia, C., Christophe, A., and Bertoncini, J. (1997). High-amplitude sucking and newborns: the quest for underlying mechanisms. J. Exp. Child Psychol. 64, 175-198. doi: 10.1006/jecp.1996.2349

Fogel, A., and Hannan, T. E. (1985). Manual actions of nine- to fifteen-week-old human infants during face-to-face interaction with their mothers. Child Dev. 56, 1271-1279.

Fujii, S., Watanabe, H., Oohashi, H., Hirashima, M., Nozaki, D., and Taga, G. (2014). Precursors of dancing and singing to music in three- to four-months-old infants. PLoS ONE 9:e103192. doi: 10.1371/journal.pone.0097680

Grönqvist, H., Brodd, K. S., and von Hofsten, C. (2011). Reaching strategies of very preterm infants at 8 months corrected age. Exp. Brain Res. 209, 225-233. doi: 10.1007/s00221-011-2538-x

Guihou, A., and Vauclair, J. (2008). Intermodal matching of vision and audition in infancy: a proposal for a new taxonomy. Eur. J. Dev. Psychol. 5, 68-91. doi: 10.1080/17405620600760409

Hadders-Algra, M., and Groothuis, A. M. C. (1999). Quality of general movements in infancy is related to neurological dysfunction, ADHD, and aggressive behaviour. Dev. Med. Child Neurol. 41, 381-391. doi: 10.1111/j.14698749.1999.tb00623.x

Hadders-Algra, M., and Prechtl, H. F. R. (1992). Developmental course of general movements in early infancy. I. Descriptive analysis of change in form. Early Hum. Dev. 28, 201-213. doi: 10.1016/0378-3782(92)90167-F

Hammer, M., and Turkewitz, G. (1975). Relationship between effective intensity of auditory stimulation and directional eye turns in the human newborn. Anim. Behav. 23, 287-290. doi: 10.1016/0003-3472(75)90077-9

Hepper, P. G., and Shahidullah, B. S. (1994). Development of fetal hearing. Arch. Dis. Child. 71, F81-F87. doi: 10.1136/fn.71.2.F81

Iverson, J. M. (2010). Developing language in a developing body: the relationship between motor development and language development. J. Child Lang. 37, 229261. doi: 10.1017/S0305000909990432

Iverson, J. M., and Fagan, M. K. (2004). Infant vocal-motor coordination: precursor to the gesture-speech system? Child Dev. 75, 1053-1066. doi: 10.1111/j.14678624.2004.00725.x

Iverson, J. M., Hall, A. J., Nickel, L., and Wozniak, R. H. (2007). The relationship between reduplicated babble onset and laterality biases in infant rhythmic arm movements. Brain Lang. 101, 198-207. doi: 10.1016/j.bandl.2006.11.004

Jouen, F. (1988). "Visual-proprioceptive control of posture in newborn infants," in Posture and Gait: Development, Adaptation and Modulation, eds B. Amblard, A. Berthoz, and F. Clarac (Amsterdam: Elsevier Science Publishers), 13-22.

Kalnins, I. V., and Bruner, J. S. (1973). The coordination of visual observation and instrumental behavior in early infancy. Perception 2, 304-314. doi: 10.1068/p020307

Kato, T., Takahashi, E., Sawada, K., Kobayashi, N., Watanabe, T., and Ishii, T. (1983). A computer analysis of infant movements synchronized with adult speech. Pediatr. Res. 17, 625-628. doi: 10.1203/00006450-198308000-00004

Keen, R. (1964). Effects of auditory stimuli on sucking behavior in the human neonate. J. Exp. Child Psychol. 1, 348-354. doi: 10.1016/0022-0965(64) 90027-X

Kisilevsky, B. S., and Hains, S. M. J. (2011). Onset and maturation of fetal heart rate response to the mother's voice over late gestation. Dev. Sci. 14, 214-223. doi: 10.1111/j.1467-7687.2010.00970.x

Korver, A. M. H., Konings, S., Dekker, F. W., Wever, C. C., Frijns, J. H. M., and Oudesluys-Murphy, A. M. (2010). Newborn hearing screening vs. later hearing. JAMA 304, 1701-1708. doi: 10.1001/jama.2010.1501

Kuhlman, K. A., Burns, K. A., Depp, R., and Sabbagha, R. E. (1988). Ultrasonic imaging of normal fetal response to external vibratory acoustic stimulation. Am. J. Obstet. Gynecol. 158, 47-51. doi: 10.1016/0002-9378(88)90773-9

Lecanuet, J. P., Granier-Deferre, C., Jacquet, A.-Y., Capponi, I., and Ledru, L. (1993). Prenatal discrimination of a male and a female voice uttering the same sentence. Early Dev. Parent. 2, 217-228. doi: 10.1002/edp.2430020405

Lecanuet, J. P., Graniere-Deferre, C., Jacquet, A.-Y., and DeCasper, A. J. (2000). Fetal discrimination of low-pitched musical notes. Dev. Psychobiol. 36, 29-39. doi: 10.1002/(SICI) 1098-2302(200001)36:1<29::AID-DEV4>3.0.CO;2-J

Lee, D. N. (2006). How Movement is Guided. Available at: http://www.pmarc.ed. ac.uk/ideas/pdf/HowMovtGuided100311.pdf, 1-64.

Lee, M.-H., and Newell, K. M. (2013). Contingent auditory feedback of arm movement facilitates reaching behavior in infancy. Infant Behav. Dev. 36, 817-824. doi: 10.1016/j.infbeh.2013.09.006 
Lipsitt, L. P., and Kay, H. (1964). Conditioned sucking in the human newborn. Psychon. Sci. 1, 29-30. doi: 10.3758/BF03342772

Locke, J. L., Bekken, K. E., Mcminnlarson, L., and Wein, D. (1995). Emergent control of manual and vocal-motor activity in relation to the development of speech. Brain Lang. 51, 498-508. doi: 10.1006/brln.1995.1073

Lockman, J. J., Ashmead, D. H., and Bushnell, E. W. (1984). The development of anticipatory hand orientation during infancy. J. Exp. Child Psychol. 37, 176-186. doi: 10.1016/0022-0965(84)90065-1

Masataka, N. (1995). The relation between index-finger extension and the acoustic quality of cooing in three-mont-old infants. J. Child Lang. 22, 247-257. doi: $10.1017 /$ S0305000900009776

McDonnell, P. M. (1975). The development of visually guided reaching. Percept. Psychophys. 18, 181-185. doi: 10.3758/BF03205963

Mendelson, M. J., and Hath, M. M. (1976). The relation between audition and vision in the human newborn. Monogr. Soc. Res. Child 41, 1-72. doi: 10.2307/1165922

Miller, C. L., and Byrne, J. M. (1983). Psychophysiologic and behavioral response to auditory stimuli in the newborn. Infant Behav. Dev. 6, 369-389. doi $10.1016 / \mathrm{S} 0163-6383(83) 80045-9$

Moore, J. K., and Linthicum, F. H. (2007). The human auditory system: a timeline of development. Int. J. Audiol. 46, 460-478. doi: 10.1080/14992020701383019

Morgan, G., Killough, C. M., and Thompson, L. A. (2013). Does visual information influence infants' movement to music? Psychol. Music 41, 249-264. doi: 10.1177/0305735611425897

Morrongiello, B. A., and Fenwick, K. D. (1994). Sound localization in newborn human infants. Dev. Psychobiol. 27, 519-538. doi: 10.1002/dev.420270805

Morrongiello, B. A., Fenwick, K. D., and Chance, G. (1998). Crossmodal learning in newborn infants: inferences about properties events of auditory-visual events. Infant Behav. Dev. 21, 543-554. doi: 10.1016/S0163-6383(98)90028-5

Muir, D., and Field, J. (1979). Newborn infants orient to sounds newborn infants orient to sounds. Child Dev. 50, 431-436. doi: 10.2307/1129419

Nakata, T., and Trehub, S. E. (2004). Infants' responsiveness to maternal speech and singing. Infant Behav. Dev. 27, 455-464. doi: 10.1016/j.infbeh.2004.03.002

Newell, K. M., Scully, D. M., McDonald, P. V., and Baillargeon, R. (1989). Task constraints and infant grip configurations. Dev. Psychobiol. 22, 817-831. doi: 10.1002/dev.420220806

Phillips-Silver, J., and Trainor, L. J. (2007). Hearing what the body feels: auditory encoding of rhythmic movement. Cognition 105, 533-546. doi: 10.1016/j.cognition.2006.11.006

Pieraut-Le Bonniec, G. (1985). From visual-motor anticipation to conceptualization: reaction to solid and hollow objects and knowledge of the function of containment. Infant Behav. Dev. 8, 413-424. doi: 10.1016/0163-6383(85) 90005-0

Rochat, P. (1983). Oral touch in young infants: response to variations of nipple characteristics in the first months of life. Int. J. Behav. Dev. 6, 123-133. doi: $10.1177 / 016502548300600201$

Rochat, P., and Hespos, S. J. (1997). Differential rooting response by neonates: evidence for an early sense of self. Early Dev. Parent. 6, 105-112. doi: 10.1002/(SICI) 1099-0917(199709/12)6:3/4<105::AID-EDP150>3.0.CO;2-U

Rönnqvist, L., and Domellöf, E. (2006). Quantitative assessment of right and left reaching movements in infants: a longitudinal study from 6 to 36 months. Dev Psychobiol. 48, 444-459. doi: 10.1002/dev.20160

Rönnqvist, L., and von Hofsten, C. (1994). Neonatal finger and arm movements as determined by a social and an object context. Early Dev. Parent. 3, 81-94. doi: 10.1002/edp.2430030205

Siddiqui, A. (1995). Object size as a determinant of grasping in infancy. J. Genet. Psychol. 156, 345-358. doi: 10.1080/00221325.1995.9914828

Siqueland, E. R., and Lipsitt, L. P. (1966). Conditioned head-turning in human newborns. J. Exp. Child Psychol. 3, 356-376. doi: 10.1016/0022-0965(66)90080-4

Smith, L. S., Dmochowski, P. A., Muir, D. W., and Kisilevsky, B. S. (2007). Estimated cardiac vagal tone predicts fetal responses to mother's and stranger's voices. Dev. Psychobiol. 49, 543-547. doi: 10.1002/dev.20229

Stanley, J. M., and Madsen, C. K. (1990). Comparison of infant preference to auditory stimuli. J. Music Ther. 27, 54-97. doi: 10.1093/jmt/27.2.54
Thelen, E. (1979). Rhythmical stereotypies in normal human infants. Anim. Behav 27, 699-715. doi: 10.1016/0003-3472(79)90006-X

Thelen, E. (1981). Rhythmical behavior in infancy: an ethological perspective. Dev. Psychol. 17, 237-257. doi: 10.1037/0012-1649.17.3.237

Thun-Hohenstein, L., and Largo, R. H. (1991). Early fine motor and adaptive development in high-risk appropriate for gestational age preterm and healthy term children. Eur. J. Pediatr. 150, 562-569. doi: 10.1007/BF02072208

Trevarthen, C. (1974). The psychobiology of speech development. Lang. Brain 12, 570-585.

Turkewitz, G., Birch, H. G., Moreau, T., Levy, L., and Cornwell, A. C. (1966). Effect of intensity of auditory stimulation on directional eye movements in the human neonate. Anim. Behav. 14, 93-101. doi: 10.1016/S0003-3472(66)80016-7

van der Meer, A. L. (1997). Keeping the arm in the limelight: advanced visual control of arm movements in neonates. Eur. J. Paediatr. Neurol. 1, 103-108. doi: 10.1016/S1090-3798(97)80040-2

van der Meer, A. L., van der Weel, F. R., and Lee, D. N. (1995). The functional significance of arm movements in neonates. Science 267, 693-695. doi: $10.1126 /$ science. 7839147

van der Meer, A. L. H., and van der Weel, F. R. R. (2011). "Auditory guided arm and whole body movements in young infants," in Advances in Sound Localization, ed. P. Strumillo (Rijeka: InTech), 297-314.

von Hofsten, C. (1984). Developmental changes in the organization of prereaching movements. Dev. Psychol. 20, 378-388. doi: 10.1037//0012-1649.20.3.378

von Hofsten, C. (1993). Prospective control: a basic aspect of action development. Hum. Dev. 36, 253-270. doi: 10.1159/000278212

von Hofsten, C., and Fazel-Zandy, S. (1984). Development of visually guided hand orientation in reaching. J. Exp. Child Psychol. 38, 208-219. doi: 10.1016/00220965(84)90122-X

von Hofsten, C., and Rönnqvist, L. (1988). Preparation for grasping an object: a developmental study. J. Exp. Psychol. 14, 610-621.

von Hofsten, C., and Rönnqvist, L. (1993). The structuring of neonatal arm movements. Child Dev. 64, 1046-1057. doi: 10.1111/j.1467-8624.1993. tb04187.x

Walton, G. E., Bower, N. J. A., and Bower, T. G. R. (1992). Recognition of familiar faces by newborns. Infant Behav. Dev. 15, 265-269. doi: 10.1016/01636383(92)80027-R

Werner, L. A. (2007). Issues in human auditory development. J. Commun. Disord. 40, 275-283. doi: 10.1016/j.jcomdis.2007.03.004

Wertheimer, M. (1961). Psychomotor coordination of auditory and visual space at birth. Science 134:1692. doi: 10.1126/science.134.3491.1692

Winkler, I., Háden, G. P., Ladinig, O., Sziller, I., and Honing, H. (2009). Newborn infants detect the beat in music. PNAS 106, 2468-2471. doi: 10.1073/pnas.0809035106

Zentner, M., and Eerola, T. (2010). Rhythmic engagement with music in infancy. PNAS 107, 5768-5773. doi: 10.1073/pnas.1000121107

Conflict of Interest Statement: The authors declare that the research was conducted in the absence of any commercial or financial relationships that could be construed as a potential conflict of interest.

Received: 20 May 2014; accepted: 01 September 2014; published online: 18 September 2014.

Citation: Ferronato PAM, Domellöf E and Rönnqvist L (2014) Early influence of auditory stimuli on upper-limb movements in young human infants: an overview. Front. Psychol. 5:1043. doi: 10.3389/fpsyg.2014.01043

This article was submitted to Developmental Psychology, a section of the journal Frontiers in Psychology.

Copyright (C) 2014 Ferronato, Domellöf and Rönnqvist. This is an open-access article distributed under the terms of the Creative Commons Attribution License (CC BY). The use, distribution or reproduction in other forums is permitted, provided the original author(s) or licensor are credited and that the original publication in this journal is cited, in accordance with accepted academic practice. No use, distribution or reproduction is permitted which does not comply with these terms. 